\title{
Enantiomeric fraction evaluation of pharmaceuticals in environmental matrices by liquid chromatography-tandem mass spectrometry
}

\author{
Ana Rita Ribeiro, Lúcia H.M.L.M. Santos, Alexandra S. Maia, \\ Cristina Delerue-Matos, Paula M.L. Castro, Maria Elizabeth Tiritan
}

\begin{abstract}
A B S T R A C T
The interest for environmental fate assessment of chiral pharmaceuticals is increasing and enantioselective analytical methods are mandatory. This study presents an enantioselective analytical method for the quantification of seven pairs of enantiomers of pharmaceuticals and a pair of a metabolite. The selected chiral pharmaceuticals belong to three different therapeutic classes, namely selective serotonin reuptake inhibitors (venlafaxine, fluoxetine and its metabolite norfluoxetine), beta-blockers (alprenolol,

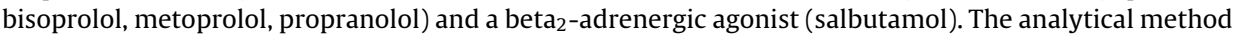
was based on solid phase extraction followed by liquid chromatography tandem mass spectrometry with a triple quadrupole analyser. Briefly, Oasis ${ }^{\circledR}$ MCX cartridges were used to preconcentrate $250 \mathrm{~mL}$ of water samples and the reconstituted extracts were analysed with a Chirobiotic ${ }^{\mathrm{TM}} \mathrm{V}$ under reversed mode. The effluent of a laboratory-scale aerobic granular sludge sequencing batch reactor (AGS-SBR) was used to validate the method. Linearity $\left(r^{2}>0.99\right)$, selectivity and sensitivity were achieved in the range of $20-400 \mathrm{ng} \mathrm{L}^{-1}$ for all enantiomers, except for norfluoxetine enantiomers which range covered $30-400 \mathrm{ng} \mathrm{L}^{-1}$. The method detection limits were between 0.65 and $11.5 \mathrm{ng} \mathrm{L}^{-1}$ and the method quantification limits were between 1.98 and $19.7 \mathrm{ng} \mathrm{L}^{-1}$. The identity of all enantiomers was confirmed using two MS/MS transitions and its ion ratios, according to European Commission Decision 2002/657/EC. This method was successfully applied to evaluate effluents of wastewater treatment plants (WWTP) in Portugal. Venlafaxine and fluoxetine were quantified as non-racemic mixtures (enantiomeric fraction / 0.5). The enantioselective validated method was able to monitor chiral pharmaceuticals in WWTP effluents and has potential to assess the enantioselective biodegradation in bioreactors. Further application in environmental matrices as surface and estuarine waters can be exploited.
\end{abstract}

\section{Introduction}

Pharmaceuticals in the environment have been extensively investigated in the last two decades [1-6]. However, the concern about the stereochemistry of chiral pharmaceuticals (CP) in the environment is more recent. The majority of publications concerning pharmaceuticals in the environment consider the pair of enantiomers as a unique molecular entity [7]. Enantiomers have different interactions with chiral molecules (e.g. enzymes) leading to different biological responses, affecting differently living organisms. The enantioselectivity in ecotoxicity and biodegradation processes is evident and comparable to the events in medical/biomedical fields [7]. The degradation of CP can be enantioselective or enantiospecific and their occurrence in the environment may be as a single or as mixtures of the two 
enantiomers. Unlike abiotic degradation, biodegradation can be enantioselective and as such accurate methods to measure the enantiomeric fraction (EF) in the environment are crucial to understand the biodegradation process and to estimate ecotoxicity of $\mathrm{CP}$. The enantioselectivity in ecotoxicity has been reported; as examples, (S)-fluoxetine $((S)$-FLX) is more toxic to Daphnia magna and Pimephales promelas than (R)-FLX [8]; chronic responses of $P$. promelas to propranolol (PHO) enantiomers supported the hypothesis of higher toxicity of (S)-PHO; the beta-blocker atenolol (ATE) was studied by De Andrés et al. [9], who found that $(R)$-enantiomer is more toxic than the $(S)$ enantiomer.

The most used technique for environmental analyses of $\mathrm{CP}$ is LC-MS/MS [10-14] using chiral stationary phases (CSPs). Some classes of CP, such as proton pump inhibitors [15,16], antifungals [17], Non Steroid Anti-Inflammatory Drugs (NSAID) [18-21], beta-blockers [10,12,22-31] as well as antidepressants and their metabolites [11-13,28-34], have been reported in environmental matrices, concerning its enantiomers. Regarding antidepressants, enantioselective biodegradation of venlafaxine (VNF) was found in a French river, with racemic VNF at the output of the main WWTP discharging into the river and with $\mathrm{EF}$ variation along the river stretch [11]. Enantiomers of FLX and its demethylated metabolite norfluoxetine (NFLX) were found in Sweden, with the concentration of $(S)$-FLX higher than (R)-FLX in both raw and treated wastewaters [13,33]. VNF was detected in all influent and effluent samples of four WWTP in United Kingdom with decreasing EF from influent to effluent [34]. The same authors reported in another study the increasing of EF of VNF and ATE from influent to effluent, indicating the enrichment of the $(R)$-ATE and the first eluting enantiomer of VNF [30]. VNF, PHO and ATE were detected with differences in EF between effluent and river waters in United Kingdom [31]. Most of the reported methods were developed to quantify only one therapeutic class; MacLeod et al. (2007) developed a reference study of enantiomeric quantification of multiclass pharmaceuticals in the environment, including some beta-blockers (ATE, MET, nadolol, pindolol, PHO, and sotalol), two selective serotonin reuptake inhibitors (citalopram and FLX) and one beta ${ }_{2}$-adrenergic agonist (salbutamol (SBT)), with EF variation for most of the target pharmaceuticals between the influent and the effluent of WWTP [28]. Later, MacLeod and Wong (2010) studied ten pharmaceuticals from different therapeutic classes and observed EF differences between WWTP for citalopram, ATE, sotalol and temazepam as well as temporal changes in EF for all drugs except for sotalol [29]. Recently, another multiclass pharmaceutical study developed by López-Serna et al. (2013) reported the stereoselective transformation of ATE in two WWTP and the predominance of $(S)$-PHO, (S)-FLX and E2 of SBT in influent, effluent and surface water samples [12]. Therefore, the assessment of EF to evaluate the environmental risk assessment, fate and effects of $\mathrm{CP}$ in the environment, is urgently required [7] and demanded by the scientific community [35].

This work presents a validated analytical method based on solid-phase extraction (SPE) with MCX cartridges, followed by enantioselective LC-MS/MS with electrospray ionization (ESI) using a triple quadrupole mass analyser, for the quantification of seven enantiomeric pairs of chiral pharmaceuticals and one pair of a metabolite using an eco-friendly mobile phase constituted by ethanol and ammonium acetate buffer. The compounds (Table 1 ) belong to three different pharmacological classes as selective serotonin reuptake inhibitors and a metabolite (VNF, FLX and its metabolite NFLX), beta-blockers (alprenolol (ALP), bisoprolol (BSP), MET, PHO) and the beta $2_{-}$ adrenergic agonist SBT. This method was able to quantify the EF of the target CP in effluents of WWTP in Portugal and in effluents of a laboratory scale aerobic granular sludge bioreactor.

\section{Experimental}

\subsection{Chemicals and materials}

Ethanol and methanol (HPLC grade) were purchased from Fisher Scientific UK Limited (Leicestershire, UK). Ammonium acetate, ammonium hydroxide $25 \%$ and formic acid were purchased from Merck (Darmstadt, Germany) and acetic acid 100\% Chromanorm (HPLC grade) from VWR International (Fontenaysous-Bois, France). Ultrapure water was supplied by a Milli-Q water system. HPLC grade solvents were filtered with $0.22 \mu \mathrm{m}$ nylon membrane filters (Membrane Solutions, La Plano, TX, USA).

Fluoxetine hydrochloride (FLX), (S)-(+)-fluoxetine hydrochloride $((S)$-FLX), norfluoxetine (NFLX), alprenolol hydrochloride (ALP), (-)-(S)-alprenolol L-tartrate hydrate ((S)-ALP), metoprolol tartrate (MET), propranolol hydrochloride (PHO), (-)(S)-propranolol ((S)-PHO), salbutamol hemisulfate (SBT), $(R)$ salbutamol hydrochloride ((R)-SBT), and bisoprolol hemifumarate (BSP) were purchased from Sigma-Aldrich (Steinhein, Germany). Venlafaxine hydrochloride (VNF), (S)-venlafaxine ((S)-VNF), $(S)$ metoprolol ((S)-MET) and (S)-norfluoxetine ((S)-NFLX) were purchased from Santa Cruz Biotechnology, Inc. (Heidelberg, Germany). All reference standards were of $>98 \%$ purity.

Stock solutions were prepared by dissolution of known amounts of standards in ethanol, to obtain a concentration of approximately $1000 \mu \mathrm{g} \mathrm{mL}^{-1}$ of the enantiomeric mixtures and $500 \mu \mathrm{g} \mathrm{mL}^{-1}$ of the individual enantiomers. All enantiomeric mixtures were racemic, excepted NFLX. The proportion of $(R)$ - and $(S)$-enantiomers of NFLX of the standard was calculated, with $35 \%$ of the $(R)$-enantiomer and $65 \%$ of the $(S)$-enantiomer, which corresponds to an EF of 0.65 . All standard solutions were stored at $-20^{\circ} \mathrm{C}$. A working standard solution containing $400 \mathrm{ng} \mathrm{mL}^{-1}$ of each enantiomer was prepared by dilution in ethanol.

The cartridges used for SPE were Oasis ${ }^{\circledR}$ MCX (Mixed-mode Cation exchange) (150 mg, $6 \mathrm{~mL}$ ) purchased from Waters (Milford, Massachusetts, USA).

\subsection{Fortified and blank samples}

Water samples of the final effluent of the secondary clarifier of a WWTP located in the North of Portugal and water samples of the effluent of a laboratory-scale aerobic granular sludge sequential batch reactor (AGS-SBR), previously fed with a range of pharmaceuticals and other fluorinated compounds [40-42] were evaluated as matrices within the method development. Due to the absence of the most target pharmaceuticals, the synthetic effluent from the AGS-SBR was chosen for method development and validation. FLX was the only compound found in the matrix.

\subsection{Solid phase extraction}

SPE was performed on Oasis® MCX $150 \mathrm{mg}$ sorbent cartridges using a Varian vacuum extraction device. The optimized SPE procedure was carried out accordingly to work published elsewhere $[2,36]$. Several sample volumes of a $220 \mathrm{ng} \mathrm{L}^{-1}$ spiked AGS-SBR sample were tested $(25,50,100,250,500,1000 \mathrm{~mL})$ to determine the adequate volume to achieve the highest recovery. Briefly, the cartridges were conditioned sequentially with $8 \mathrm{~mL}$ of methanol and $8 \mathrm{~mL}$ of ultrapure water, at a flow rate of $1 \mathrm{~mL} \mathrm{~min}^{-1}$. The effluent samples were filtered with $0.45 \mu \mathrm{m}$ Glass microfiber filters (Whatman ${ }^{\mathrm{TM}}$ ), acidified at $\mathrm{pH} 2$, adjusted with sulphuric acid, and then were percolated through the cartridges at a constant flow rate of $10 \mathrm{~mL} \mathrm{~min}^{-1}$ using a vacuum manifold system connected to a vacuum pump. Then, the wash step was performed with $8 \mathrm{~mL}$ of aqueous solution of $2 \%$ formic acid. The cartridges 
Table 1

Chemical structures, molecular formula, molecular weights ( $\mathrm{Mw})$ and $\mathrm{pKa}$ of the selected chiral pharmaceuticals and metabolite.

\begin{tabular}{|c|c|c|c|}
\hline Compound & Chemical structure & Molecular formula/Mw & $\mathrm{pKa}$ \\
\hline$R / S( \pm$ )-fluoxetine (FLX) & & $\mathrm{C}_{17} \mathrm{H}_{18} \mathrm{~F}_{3} \mathrm{NO} / 309.33 \mathrm{~g} \mathrm{~mol}^{-1}$ & $10.05[36]$ \\
\hline$R / S( \pm)$-norfluoxetine (NFLX) & & $\mathrm{C}_{16} \mathrm{H}_{16} \mathrm{~F}_{3} \mathrm{NO} / 295.30 \mathrm{~g} \mathrm{~mol}^{-1}$ & $9.05[36]$ \\
\hline$R / S( \pm)$-venlafaxine $(\mathrm{VNF})$ & & $\mathrm{C}_{17} \mathrm{H}_{27} \mathrm{~F}_{3} \mathrm{NO}_{2} / 277.40 \mathrm{~g} \mathrm{~mol}^{-1}$ & $10.09[38]$ \\
\hline$R / S( \pm$ )-alprenolol (ALP) & & $\mathrm{C}_{15} \mathrm{H}_{23} \mathrm{NO}_{2} / 249.35 \mathrm{~g} \mathrm{~mol}^{-1}$ & $9.19[37]$ \\
\hline$R / S( \pm$ )-bisoprolol (BSP) & & $\mathrm{C}_{18} \mathrm{H}_{31} \mathrm{NO}_{4} / 325.44 \mathrm{~g} \mathrm{~mol}^{-1}$ & $9.50[37]$ \\
\hline$R / S( \pm)$-metoprolol (MET) & & $\mathrm{C}_{15} \mathrm{H}_{25} \mathrm{NO}_{3} / 267.36 \mathrm{~g} \mathrm{~mol}^{-1}$ & $9.60[37]$ \\
\hline$R / S( \pm)$-propranolol (PHO) & & $\mathrm{C}_{16} \mathrm{H}_{21} \mathrm{NO}_{2} / 259.16 \mathrm{~g} \mathrm{~mol}^{-1}$ & $9.15[37]$ \\
\hline$R / S( \pm)$-salbutamol (SBT) & & $\mathrm{C}_{13} \mathrm{H}_{21} \mathrm{NO}_{3} / 239.31 \mathrm{~g} \mathrm{~mol}^{-1}$ & $9.30[39]$ \\
\hline
\end{tabular}

were dried under vacuum for 30 min to dry out residual water. Elution was performed in two steps, both at $1 \mathrm{~mL} \mathrm{~min}^{-1}$, the first with $8 \mathrm{~mL}$ of methanol to elute acids and neutrals, which was wasted. The second step of elution was performed with $8 \mathrm{~mL}$ of methanolic solution of $5 \%$ ammonium hydroxide to elute the basic compounds, which included the target analytes. The latter extracts were evaporated to dryness in a vacuum concentrator, model Centrivap Centrifugal concentrator with cold trap $\left(-50^{\circ} \mathrm{C}\right.$ model) (Labconco, Kansas City, USA). The residues were dissolved in $1000 \mu \mathrm{L}$ of ethanol and filtered by $0.22 \mu \mathrm{m}$ Polytetrafluoroethylene (PTFE) syringe filters (Membrane Solutions, La Plano, TX, USA).

\subsection{LC-MS/MS analysis}

Chromatographic analysis were performed using a Shimadzu UHPLC Nexera System equipped with two Pumps LC-30AD, an Autosampler SIL-30AC, an Oven CTO-20AC, a Degasser DGU-20A a System Controller CBM-20A, a LC Solution Version 5.41SP1 (Shimadzu Corporation, Tokyo, Japan) and a triple quadrupole mass spectrometer detector Shimadzu LCMS-8030 coupled to the LC System.

An electrospray ionization (ESI) source operating in positive ionization mode was used. The direct injection of each compound at a $10,000 \mu \mathrm{g} \mathrm{L}^{-1}$ concentration was performed to select the precursor 
Table 2

Selected reaction monitoring (SRM) instrument parameters for tandem mass spectrometry analysis of target analytes.

\begin{tabular}{|c|c|c|c|c|c|c|c|c|c|c|}
\hline \multirow[t]{2}{*}{ Compound } & \multirow[t]{2}{*}{ Precursor ion $(\mathrm{m} / \mathrm{z})$} & \multicolumn{4}{|c|}{ Quantification (first transition) } & \multicolumn{4}{|c|}{ Confirmation (second transition) } & \multirow[t]{2}{*}{ Ion ratio $( \pm \mathrm{SD}) \mathrm{n}=9$} \\
\hline & & Product Ion & $\mathrm{DP}^{\mathrm{a}}(\mathrm{V})$ & $\mathrm{CE}^{\mathrm{b}}(\mathrm{V})$ & $\overline{\operatorname{CXP}^{c}(V)}$ & Product Ion & $\mathrm{DP}^{\mathrm{a}}(\mathrm{V})$ & $C E^{b}(V)$ & $\overline{\operatorname{CXP}^{c}(V)}$ & \\
\hline $\begin{array}{l}(S)-\mathrm{FLX} \\
(R)-\mathrm{FLX}\end{array}$ & $310.20[\mathrm{M}+\mathrm{H}]^{+}$ & 44.15 & -15 & -14 & -17 & 148.20 & -15 & -9 & -16 & $\begin{array}{l}13.9( \pm 0.64) \\
14.2( \pm 0.62)\end{array}$ \\
\hline $\begin{array}{l}\text { (S)-NFLX } \\
(R)-\mathrm{NFLX}\end{array}$ & $296.30[\mathrm{M}+\mathrm{H}]^{+}$ & 134.10 & -15 & -8 & -13 & 30.25 & -15 & -12 & -11 & $\begin{array}{l}1.18( \pm 0.06) \\
1.20( \pm 0.09)\end{array}$ \\
\hline $\begin{array}{l}(S)-\mathrm{VNF} \\
(R)-\mathrm{VNF}\end{array}$ & $278.00[\mathrm{M}+\mathrm{H}]^{+}$ & 58.10 & -30 & -21 & -22 & 260.25 & -30 & -13 & -18 & $\begin{array}{l}4.47( \pm 0.15) \\
4.50( \pm 0.26)\end{array}$ \\
\hline $\begin{array}{l}(R)-\mathrm{SBT} \\
(S) \text {-SBT }\end{array}$ & $240.20[\mathrm{M}+\mathrm{H}]^{+}$ & 148.15 & -30 & -20 & -15 & 222.20 & -30 & -11 & -15 & $\begin{array}{l}1.90( \pm 0.12) \\
1.91( \pm 0.11)\end{array}$ \\
\hline $\begin{array}{l}(S) \text {-ALP } \\
(R)-A L P\end{array}$ & $250.10[\mathrm{M}+\mathrm{H}]^{+}$ & 116.10 & -17 & -18 & -23 & 72.20 & -17 & -22 & -13 & $\begin{array}{l}0.96( \pm 0.03) \\
0.95( \pm 0.05)\end{array}$ \\
\hline $\begin{array}{l}\text { BSP E1 }{ }^{d} \\
\text { BSP E2 }\end{array}$ & $326.20[\mathrm{M}+\mathrm{H}]^{+}$ & 116.15 & -28 & -20 & -23 & 74.15 & -28 & -26 & -14 & $\begin{array}{l}2.43( \pm 0.09) \\
2.45( \pm 0.07)\end{array}$ \\
\hline $\begin{array}{l}(S) \text {-MET } \\
(R)-\mathrm{MET}\end{array}$ & $268.00[\mathrm{M}+\mathrm{H}]^{+}$ & 72.15 & -24 & -24 & -14 & 116.20 & -24 & -20 & -23 & $\begin{array}{l}1.16( \pm 0.12) \\
1.18( \pm 0.05)\end{array}$ \\
\hline $\begin{array}{l}\text { (S)-PHO } \\
(R)-\mathrm{PHO}\end{array}$ & $260.10[\mathrm{M}+\mathrm{H}]^{+}$ & 116.15 & -21 & -20 & -24 & 56.10 & -21 & -31 & -20 & $\begin{array}{l}1.14( \pm 0.08) \\
1.18( \pm 0.05)\end{array}$ \\
\hline
\end{tabular}

a DP is the declustering potential.

b $\mathrm{CE}$ is the collision energy.

c CXP is the collision cell exit potential.

d $\mathrm{E} 1$ is the first-eluted enantiomer.

e $\mathrm{E} 2$ is the second-eluted enantiomer.

ion through full scan mode. Then the direct injection of individual standard solutions of each compound at $1000 \mu \mathrm{g} \mathrm{L}^{-1}$ allowed to choose the most abundant fragments and to optimize the mass spectrometer parameters for each compound (declustering potential, collision energy and collision cell exit potential). Quantification was based on selected reaction monitoring (SRM), with the two SRM transitions between the precursor ion and the most abundant fragment ions for each analyte selected, being the most abundant used as quantifier and the second most abundant as qualifier, with a scan time of $100 \mathrm{~ms}$ per transition (Table 2). The parameters capillary voltage, drying gas flow, nebulizing gas flow, desolvation temperature and source temperature were optimized, injecting the mixture of all target compounds: capillary voltage, $1.5 \mathrm{kV}$; drying gas flow, $12.5 \mathrm{~L} \mathrm{~min}^{-1}$; nebulizing gas flow, $2.0 \mathrm{~L} \mathrm{~min}^{-1}$; desolvation temperature $475^{\circ} \mathrm{C}$ and source temperature $300^{\circ} \mathrm{C}$.

The enantioselective LC-MS/MS method developed comprises a Chiral Stationary Phase (CSP) which was an Astec Chirobiotic ${ }^{\mathrm{TM}} \mathrm{V}$, $5 \mu \mathrm{m}(150 \times 2.1 \mathrm{~mm}$ i.d.) supplied by SUPELCO Analytical (SigmaAldrich, Steinhein, Germany) and a mobile phase composed by ethanol $/ 10 \mathrm{mM}$ aqueous ammonium acetate buffer (92.5/7.5, $\mathrm{v} / \mathrm{v}), \mathrm{pH} 6.8$, performed at isocratic mode with a flow rate of $0.32 \mathrm{~mL} \mathrm{~min}^{-1}$. The $\mathrm{pH}$ adjustments were done with $\mathrm{pH}$ meter $\mathrm{HI}$ $2210 \mathrm{pH} /{ }^{\circ} \mathrm{C}$ Bench Meter from Hanna Instruments. Column oven and autosampler were set at $20^{\circ} \mathrm{C}$ and $4{ }^{\circ} \mathrm{C}$, respectively. Volume of injection was $5 \mu \mathrm{L}$.

The elution order was established based on the injection of solutions of each enantiomer separately, except for BSP.

Enantioresolution was calculated for the separation of the target chiral compounds (Table 3 ) as follows:

$\mathrm{Rs}=1.177 \frac{\left(t_{\mathrm{R}} \mathrm{E} 2-t_{\mathrm{R}} \mathrm{E} 1\right)}{\left(W_{(1 / 2)} \mathrm{E} 1+W_{(1 / 2)} \mathrm{E} 2\right)}$

where $t_{R}$ E1 and $t_{R}$ E2 are the retention times of the first and the second eluted enantiomers, respectively, and $W_{(1 / 2)}$ E1 and $W_{(1 / 2)}$ E2 are the peak widths at the half height. Six replicates were used to calculate the standard deviation of the retention time and of the enantioresolution.

The enantiomeric fraction (EF) was used to express enantioselectivity, $\mathrm{C}(S)$ and $\mathrm{C}(R)$ being the concentration of the $(S)$ and
$(R)$ enantiomers of the $\mathrm{CP}$, when the elution order was known, as described in Equation 2.

$\mathrm{EF}=\frac{\mathrm{C}(S)}{(\mathrm{C}(S)+\mathrm{C}(R))}$

When the elution order is unknown the EF was calculated, with $C(\mathrm{E} 1)$ and $C(\mathrm{E} 2)$ being the concentration of the first and second eluted enantiomers of the $\mathrm{CP}$, as described in Equation 3.

$\mathrm{EF}=\frac{C(\mathrm{E} 1)}{(C(\mathrm{E} 1)+C(\mathrm{E} 2))}$

\subsection{Method validation parameters}

The method was validated according to previous works $[2,36,43-46]$ considering the following parameters: selectivity, linearity and range, limits of detection and quantification, accuracy, recovery and precision.

Selectivity was verified by comparing the chromatograms of standards dissolved in ethanol, standards extracted from the spiked WWTP effluent, standards extracted from the spiked AGS-SBR effluent and blank extracts (non-spiked sample) of WWTP and AGS-SBR effluents. Spiked matrices as three quality control (QC) standard solutions, with three different concentrations $(80,220$ and $380 \mathrm{ng} \mathrm{L}^{-1}$ ) in triplicate for all enantiomers, were used for the recovery assays and the evaluation of efficiency of the extraction in both matrices. Recovery was calculated by comparing the peak areas of the standards from the spiked matrix obtained by SPE

Table 3

Average and standard deviation of retention time and enantioresolution (Rs).

\begin{tabular}{|c|c|c|c|}
\hline $\begin{array}{l}\text { Compound } / 1 \text { st } \\
\text { eluted enantiomer }\end{array}$ & $\begin{array}{l}\text { Retention time (1st } \\
\text { enantiomer) } \\
( \pm \mathrm{SD})^{\mathrm{b}}\end{array}$ & $\begin{array}{l}\text { Retention time } \\
\text { (2nd enantiomer) } \\
( \pm \mathrm{SD})^{\mathrm{b}}\end{array}$ & Rs \\
\hline $\mathrm{FLX} /(S)-\mathrm{FLX}$ & $19.3( \pm 0.01)$ & $23.1( \pm 0.02)$ & $1.85( \pm 0.02)$ \\
\hline NFLX/(S)-NFLX & $14.4( \pm 0.05)$ & $16.2( \pm 0.09)$ & $1.17( \pm 0.04)$ \\
\hline $\mathrm{VNF} /(S)-\mathrm{VNF}$ & $19.9( \pm 0.05)$ & $24.3( \pm 0.11)$ & $1.79( \pm 0.05)$ \\
\hline $\mathrm{SBT} /(R)-\mathrm{SBT}$ & $11.4( \pm 0.04)$ & $13.9( \pm 0.06)$ & $1.60( \pm 0.08)$ \\
\hline ALP/(S)-ALP & $12.5( \pm 0.01)$ & $14.5( \pm 0.08)$ & $1.47( \pm 0.10)$ \\
\hline BSP/BSP E1 ${ }^{\text {a }}$ & $14.4( \pm 0.01)$ & $16.7( \pm 0.03)$ & $1.37( \pm 0.02)$ \\
\hline $\mathrm{MET} /(S)-\mathrm{MET}$ & $15.7( \pm 0.06)$ & $18.3( \pm 0.09)$ & $1.53( \pm 0.15)$ \\
\hline $\mathrm{PHO} /(S)-\mathrm{PHO}$ & $16.4( \pm 0.06)$ & $19.4( \pm 0.06)$ & $1.60( \pm 0.07)$ \\
\hline
\end{tabular}

a $\mathrm{E} 1$ is the first-eluted enantiomer.

b $\mathrm{SD}$ is the standard deviation $(n=6)$. 
with those of similar concentrations in ethanolic standard solutions. Non-spiked samples were also analysed and the levels of $\mathrm{CP}$ detected were subtracted from those obtained with the spiked matrix. The AGS-SBR samples presented only the enantiomers of FLX and were used for validation purposes. Spiked samples of $250 \mathrm{~mL}$ were used for external matrix calibration standards and were prepared as described above for the SPE procedure. Linearity and range were evaluated using calibration curves prepared in triplicate with a set of eight different standard concentrations of enantiomers in the spiked AGS-SBR samples: 20; 30; 40; $60 ; 100 ; 200 ; 300 ; 400 \mathrm{ng} \mathrm{L}^{-1}$. Calibration curves were drawn by the injection of $5 \mu \mathrm{L}$ of the reconstituted $1000 \mu \mathrm{L}$ extract dissolved in ethanol. Instrument detection limits (IDL) and instrument quantification limits (IQL) were calculated from spiked samples through the signal-to-noise $(\mathrm{S} / \mathrm{N})$ ratio of 3.3 for IDL and 10 for IQL. Method detection limits (MDL) and method quantification limits (MQL) were assessed dividing, respectively IDL and IQL by the pre-concentration factor of 250.

Three QC standard solutions, with three different concentrations $\left(80,220\right.$ and $\left.380 \mathrm{ng} \mathrm{L}^{-1}\right)$ of all enantiomers, each one in triplicate, were prepared to assess the accuracy and intra- and inter-batch precision. The accuracy of the method was evaluated as the percentage of agreement between the concentrations of the standards analysed in the SPE extracts and the nominal concentration $[2,43,47]$. Precision was expressed by the relative standard deviation (RSD) of the replicate measurements.

\subsection{Matrix effect evaluation}

The post-extraction addition method to assess the matrix effect was based on a previous published work [43]. The method was carried out on laboratory-scale AGS-SBR samples, by the injection of two extracted samples, spiked with all enantiomers $\left(220 \mathrm{ng} \mathrm{L}^{-1}\right)$ (A). The areas obtained were compared with the areas obtained for an ethanolic solution with all enantiomers at the same concentration as the reconstituted spiked extracted samples (B). Two additional non-spiked samples were also extracted and analysed. The matrix effect (ME) ratio was obtained by the equation: ME $(\%)=A / B \times 100[43]$. A value of $100 \%$ indicates the absence of absolute matrix effect; ME $>100 \%$ indicates an ionization enhancement; $\mathrm{ME}<100 \%$ indicates an ionization suppression.

\subsection{Quantification in WWTP effluents}

Water samples of the final effluent of the secondary clarifier of three WWTP located on the North of Portugal, were collected in pre-rinsed amber glass bottles $(2 \mathrm{~L})$ and transported at $4{ }^{\circ} \mathrm{C}$ to the laboratory. The WWTP1 combines an anoxic reactor and an activated sludge treatment, serves 17,000 people with a maximum flow of $34.7 \mathrm{~L} \mathrm{~s}^{-1}$ and receives $18.6 \%$ of industrial wastewater. The WWTP2 combines Light Expanded Clay Aggregate (LECA ${ }^{\circledR}$ ) and an activated sludge treatment, serves 46,000 people with a maximum flow of $62.5 \mathrm{~L} \mathrm{~s}^{-1}$ and receives $39.1 \%$ of industrial wastewater. The WWTP3 only comprises an activated sludge treatment, serves a population of 80,000 with a maximum flow of $208 \mathrm{~L} \mathrm{~s}^{-1}$.

Upon reception, samples were vacuum filtered through $0.45 \mu \mathrm{m}$ nylon membrane filters (Whatman, UK) and stored at $-20^{\circ} \mathrm{C}$ until extraction as described in section 2.3 , being $5 \mu \mathrm{L}$ of the reconstituted extract analysed by LC-MS/MS.

\section{Results and discussion}

\subsection{Enantiomeric resolution}

Chromatographic enantioseparation was achieved using a mixture of ethanol and a $10 \mathrm{mM}$ aqueous ammonium acetate buffer
(92.5/7.5, v/v), pH 6.8, as mobile phase. An isocratic procedure was achieved using the vancomycin-based CSP (Chirobiotic ${ }^{\mathrm{TM}} \mathrm{V}$ column) with $150 \times 2.1 \mathrm{~mm}$ i.d., with a flow rate of $0.32 \mathrm{~mL} \mathrm{~min}^{-1}$ and the column oven set at $20^{\circ} \mathrm{C}$. Several attempts were performed to achieve the best condition for enantiomeric resolution, as varying the proportion of ethanol, the column oven temperature and the flow rate, in order to achieve enantioseparation for all target pharmaceuticals within the shortest elution time. The conditions established used ethanol as organic solvent as recommend by green chromatography method development directives [48]. The enantioseparation of sixteen enantiomers of multi-therapeutic classes using ethanol and ammonium acetate buffer with a low flow rate $\left(0.32 \mathrm{~mL} \mathrm{~min}^{-1}\right)$ was achieved in 30 minutes (Fig. 1$)$. This can be considered a great improvement when comparing with published enantioseparation for environmental application analyses [28,29,49], since MCX cartridges are more indicated for basic compounds, allowing to reduce the matrix effects. Furthermore, a short elution time was achieved with ethanol in the mobile phase, which is an eco-friendly solvent choice.

The injection of the single enantiomer standards (S)-FLX, $(S)$-NFLX, $(S)$-VNF, (S)-ALP, (S)-MET, ( $S$ )-PHO and $(R)$-SBT was performed to define the elution order of the enantiomers. These enantiomers were the first to elute in the chromatographic run. The enantioresolutions (Rs) obtained in this work are generally higher than 1.5, except for NFLX (1.17), BSP (1.37) and ALP (1.47) (Table 3). Lower elution time and better Rs values were observed comparing with those achieved in recent studies employing the same CSP [12]. The use of ethanol, an eco-friendly mobile phase in reversed elution mode presented better chromatographic parameters than methanol or tetrahydrofuran as a mobile phase $[11,12,27,28,30,49]$.

\subsection{LC-MS/MS optimization}

First of all, single direct injection of each target $\mathrm{CP}$ was performed to select the precursor ion by full scan, and then the two most abundant transitions for each compound were chosen. The protonated molecular ion of each compound was chosen as precursor ion. The most abundant product ion from each precursor ion (SRM1) was selected for quantification. The retention time and the most abundant secondary transition (SRM2) were used for confirmation purposes. The optimized mass spectrometer parameters including two SRMs, declustering potential (DP), collision energy (CE), collision cell exit potential (CXP) and ion ratio for each compound in positive ionization mode, are given in Table 2.

\subsection{Method validation}

The enantioselective method was validated according to international criteria and work published elsewhere [2,36, 43-46]. The recovery, accuracy, intra and inter-batch precision are presented in Table 4 . The best recovery values were achieved with $250 \mathrm{~mL}$ of sample. The breakthrough volume was determined by testing different volumes $(25,50,100,250,500,1000 \mathrm{~mL})$ of a $220 \mathrm{ng} \mathrm{L}^{-1}$ spiked AGS-SBR sample and correlating the volumes with the corresponding chromatographic peak areas for all enantiomers. The results showed that the breakthrough volume was reached for most enantiomers above $250 \mathrm{~mL}$, meaning that maximum extraction efficiency was obtained for this sample volume and above it the extraction efficiency declined, this phenomenon was previously observed by Bielicka-Daszkiewicz et al. (2009) [50]. The recoveries obtained with laboratory-scale AGS-SBR effluent were between $47.6 \%$ and $109 \%$ (Table 4). Enantiomers of FLX were found in the matrix and were subtracted for recovery rate calculation. Three QC standard solutions, with three different concentrations (80, 220 and $380 \mathrm{ng} \mathrm{L}^{-1}$ ) of all enantiomers spiked in the effluent samples of the laboratory AGS-SBR, each one in triplicate, were prepared 

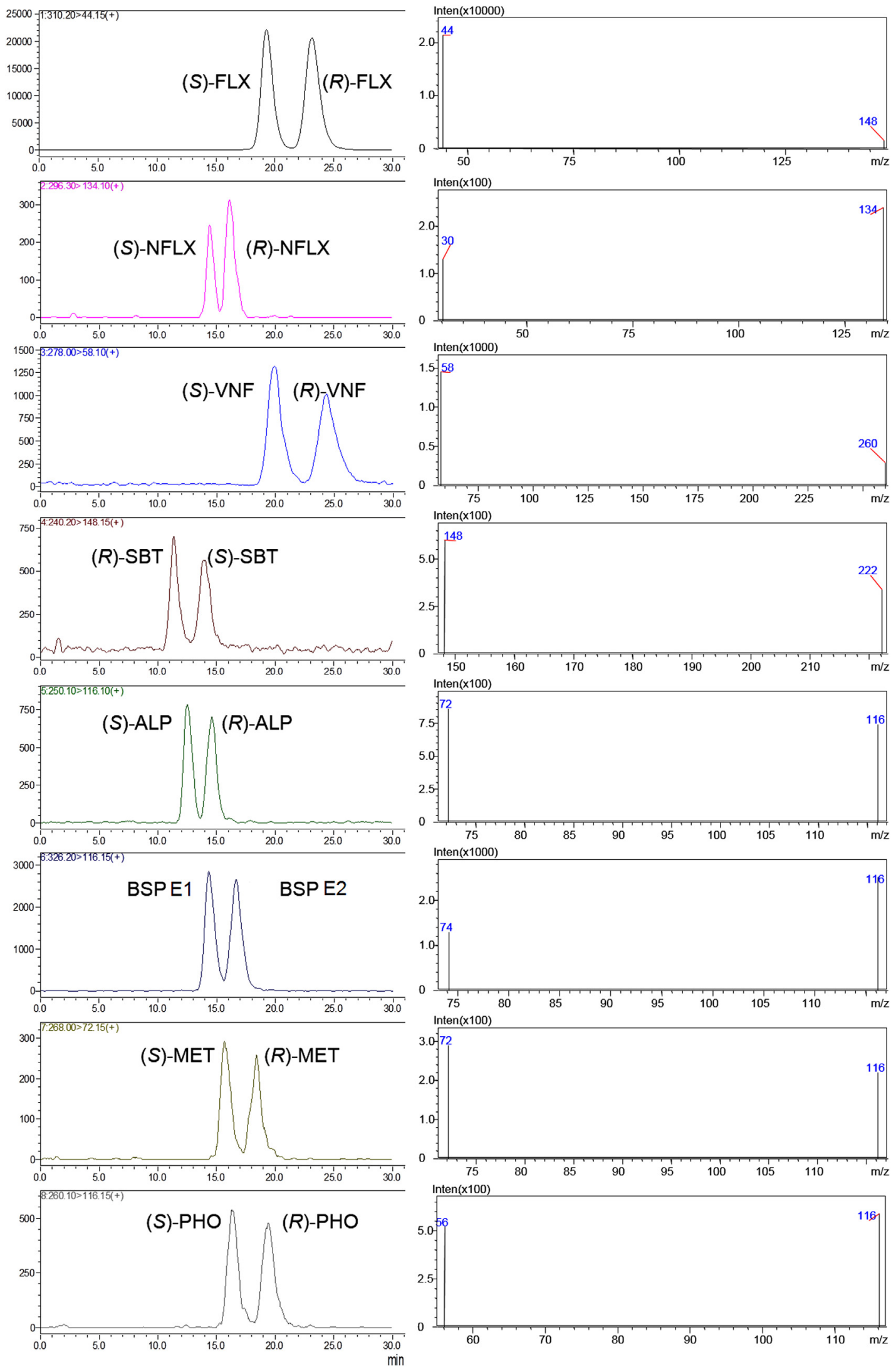

Fig. 1. Mass chromatograms and mass spectra of laboratory-scale AGS-SBR samples spiked with $60 \mathrm{ng} \mathrm{L}^{-1}$ of all enantiomers after SPE extraction on MCX cartridges. 
Table 4

Recovery, accuracy, intra and inter-batch precision.

\begin{tabular}{|c|c|c|c|c|c|c|c|c|c|}
\hline \multirow[t]{2}{*}{ Compound } & \multirow[t]{2}{*}{ Concentration } & \multirow[t]{2}{*}{ Recovery (\%) } & \multirow[t]{2}{*}{$\mathrm{RSD}^{\mathrm{a}}(\%)$} & \multicolumn{2}{|l|}{ 1st day } & \multicolumn{2}{|l|}{ 2nd day } & \multicolumn{2}{|l|}{ 3rd day } \\
\hline & & & & Acccuracy (\%) & $\mathrm{RSD}^{\mathrm{a}}(\%)$ & Acccuracy (\%) & $\mathrm{RSD}^{\mathrm{a}}(\%)$ & Acccuracy (\%) & $\mathrm{RSD}^{\mathrm{a}}(\%)$ \\
\hline \multirow[t]{3}{*}{$(S)-F L X$} & $80 \mathrm{ng} \mathrm{L}^{-1}$ & 80.1 & 11.2 & 80.8 & 10.1 & 80.2 & 3.15 & 88.5 & 11.1 \\
\hline & $220 \mathrm{ng} \mathrm{L}^{-1}$ & 91.3 & 4.27 & 80.2 & 2.90 & 82.7 & 4.46 & 80.1 & 1.40 \\
\hline & $380 \mathrm{ng} \mathrm{L}^{-1}$ & 93.2 & 3.33 & 80.2 & 2.32 & 81.2 & 3.22 & 89.0 & 2.43 \\
\hline \multirow[t]{3}{*}{$(R)$-FLX } & $80 \mathrm{ng} \mathrm{L}^{-1}$ & 92.0 & 12.2 & 82.5 & 8.68 & 92.3 & 7.11 & 82.2 & 18.0 \\
\hline & $220 \mathrm{ng} \mathrm{L}^{-1}$ & 88.4 & 5.39 & 80.4 & 10.7 & 80.8 & 5.24 & 83.3 & 8.92 \\
\hline & $380 \mathrm{ng} \mathrm{L}^{-1}$ & 97.1 & 7.38 & 84.2 & 8.32 & 82.7 & 2.24 & 98.0 & 2.51 \\
\hline \multirow[t]{3}{*}{ (S)-NFLX } & $80 \mathrm{ng} \mathrm{L}^{-1}$ & 71.3 & 12.1 & 79.9 & 6.26 & 82.6 & 14.7 & 80.2 & 3.24 \\
\hline & $220 \mathrm{ng} \mathrm{L}^{-1}$ & 81.4 & 6.90 & 80.3 & 2.35 & 94.6 & 7.55 & 81.4 & 5.82 \\
\hline & $380 \mathrm{ng} \mathrm{L}^{-1}$ & 80.8 & 6.22 & 80.1 & 1.52 & 94.5 & 11.3 & 81.8 & 4.10 \\
\hline \multirow[t]{3}{*}{$(R)-\mathrm{NFLX}$} & $80 \mathrm{ng} \mathrm{L}^{-1}$ & 81.6 & 9.79 & 87.4 & 5.98 & 83.0 & 5.48 & 87.1 & 6.63 \\
\hline & $220 \mathrm{ng} \mathrm{L}^{-1}$ & 90.8 & 6.17 & 80.2 & 3.17 & 80.1 & 2.61 & 80.3 & 6.30 \\
\hline & $380 \mathrm{ng} \mathrm{L}^{-1}$ & 91.9 & 5.21 & 80.4 & 1.27 & 80.0 & 1.13 & 80.4 & 2.97 \\
\hline \multirow[t]{3}{*}{$(S)-\mathrm{VNF}$} & $80 \mathrm{ng} \mathrm{L}^{-1}$ & 81.7 & 9.79 & 103 & 1.87 & 95.2 & 15.7 & 98.0 & 8.39 \\
\hline & $220 \mathrm{ng} \mathrm{L}^{-1}$ & 82.2 & 6.24 & 98.2 & 7.28 & 80.5 & 4.93 & 98.6 & 7.53 \\
\hline & $380 \mathrm{ng} \mathrm{L}^{-1}$ & 89.4 & 3.20 & 103 & 3.42 & 80.8 & 1.22 & 111 & 3.39 \\
\hline \multirow[t]{3}{*}{$(R)-\mathrm{VNF}$} & $80 \mathrm{ng} \mathrm{L}^{-1}$ & 78.5 & 11.1 & 101 & 0.56 & 93.5 & 17.2 & 99.2 & 8.38 \\
\hline & $220 \mathrm{ng} \mathrm{L}^{-1}$ & 83.4 & 4.71 & 97.3 & 6.89 & 81.4 & 1.87 & 98.0 & 5.08 \\
\hline & $380 \mathrm{ng} \mathrm{L}^{-1}$ & 88.2 & 7.55 & 99.6 & 5.25 & 80.4 & 9.05 & 111 & 3.04 \\
\hline \multirow[t]{3}{*}{ (R)-SBT } & $80 \mathrm{ng} \mathrm{L}^{-1}$ & 47.6 & 7.78 & 92.6 & 6.69 & 98.1 & 10.1 & 108 & 5.03 \\
\hline & $220 \mathrm{ng} \mathrm{L}^{-1}$ & 58.6 & 5.27 & 85.5 & 3.81 & 99.9 & 3.81 & 112 & 5.05 \\
\hline & $380 \mathrm{ng} \mathrm{L}^{-1}$ & 64.9 & 4.31 & 97.2 & 2.30 & 103 & 3.08 & 118 & 9.11 \\
\hline \multirow[t]{3}{*}{ (S)-SBT } & $80 \mathrm{ng} \mathrm{L}^{-1}$ & 50.6 & 8.95 & 88.7 & 7.05 & 81.4 & 10.1 & 96.1 & 11.4 \\
\hline & $220 \mathrm{ng} \mathrm{L}^{-1}$ & 59.1 & 6.01 & 81.4 & 4.95 & 97.9 & 5.10 & 111 & 14.2 \\
\hline & $380 \mathrm{ng} \mathrm{L}^{-1}$ & 65.2 & 5.60 & 83.7 & 2.07 & 99.0 & 3.06 & 115 & 11.9 \\
\hline \multirow[t]{3}{*}{$(S)$-ALP } & $80 \mathrm{ng} \mathrm{L}^{-1}$ & 75.2 & 9.96 & 93.8 & 4.56 & 94.5 & 18.4 & 103 & 8.33 \\
\hline & $220 \mathrm{ng} \mathrm{L}^{-1}$ & 97.3 & 4.29 & 91.8 & 6.22 & 94.8 & 2.12 & 103 & 6.70 \\
\hline & $380 \mathrm{ng} \mathrm{L}^{-1}$ & 99.4 & 3.21 & 98.2 & 2.28 & 93.3 & 1.31 & 115 & 1.85 \\
\hline \multirow[t]{3}{*}{$(R)-\mathrm{ALP}$} & $80 \mathrm{ng} \mathrm{L}^{-1}$ & 77.9 & 10.7 & 94.2 & 3.37 & 94.6 & 18.7 & 101 & 7.44 \\
\hline & $220 \mathrm{ng} \mathrm{L}^{-1}$ & 95.4 & 5.03 & 87.6 & 6.70 & 98.8 & 4.59 & 106 & 8.36 \\
\hline & $380 \mathrm{ng} \mathrm{L}^{-1}$ & 102 & 2.84 & 93.2 & 1.16 & 94.7 & 3.09 & 113 & 1.24 \\
\hline \multirow[t]{3}{*}{$\mathrm{BSP}_{\mathrm{E}}{ }^{\mathrm{b}}$} & $80 \mathrm{ng} \mathrm{L}^{-1}$ & 76.6 & 8.74 & 81.7 & 3.06 & 81.5 & 16.2 & 84.4 & 3.46 \\
\hline & $220 \mathrm{ng} \mathrm{L}^{-1}$ & 96.8 & 4.80 & 79.6 & 5.82 & 79.3 & 4.44 & 91.6 & 3.37 \\
\hline & $380 \mathrm{ng} \mathrm{L}^{-1}$ & 102 & 3.49 & 84.9 & 1.59 & 80.3 & 1.32 & 98.8 & 1.89 \\
\hline \multirow[t]{3}{*}{ BSP E2 ${ }^{c}$} & $80 \mathrm{ng} \mathrm{L}^{-1}$ & 74.9 & 7.59 & 79.8 & 2.07 & 82.0 & 16.0 & 85.5 & 5.19 \\
\hline & $220 \mathrm{ng} \mathrm{L}^{-1}$ & 96.5 & 5.13 & 80.2 & 5.99 & 83.8 & 1.94 & 90.5 & 3.65 \\
\hline & $380 \mathrm{ng} \mathrm{L}^{-1}$ & 100 & 3.93 & 84.6 & 1.68 & 82.2 & 4.11 & 99.0 & 1.76 \\
\hline$(S)-\mathrm{MET}$ & $80 \mathrm{ng} \mathrm{L}^{-1}$ & 77.4 & 4.10 & 79.9 & 1.82 & 81.1 & 2.84 & 85.8 & 3.68 \\
\hline & $220 \mathrm{ng} \mathrm{L}^{-1}$ & 99.6 & 8.20 & 80.8 & 7.61 & 89.1 & 6.52 & 94.4 & 4.95 \\
\hline & $380 \mathrm{ng} \mathrm{L}^{-1}$ & 104 & 4.26 & 79.3 & 2.48 & 86.0 & 4.60 & 103 & 1.95 \\
\hline$(R)-\mathrm{MET}$ & $80 \mathrm{ng} \mathrm{L}^{-1}$ & 84.7 & 3.42 & 84.0 & 4.02 & 81.1 & 13.0 & 94.1 & 4.22 \\
\hline & $220 \mathrm{ng} \mathrm{L}^{-1}$ & 105 & 7.12 & 80.7 & 2.92 & 89.1 & 0.71 & 92.2 & 6.78 \\
\hline & $380 \mathrm{ng} \mathrm{L}^{-1}$ & 109 & 5.14 & 80.9 & 0.11 & 86.0 & 7.52 & 103 & 3.36 \\
\hline (S)-PHO & $80 \mathrm{ng} \mathrm{L}^{-1}$ & 71.9 & 5.87 & 79.8 & 2.56 & 79.4 & 7.51 & 80.5 & 2.86 \\
\hline & $220 \mathrm{ng} \mathrm{L}^{-1}$ & 90.0 & 3.45 & 80.2 & 2.77 & 80.2 & 3.40 & 82.5 & 3.96 \\
\hline & $380 \mathrm{ng} \mathrm{L}^{-1}$ & 93.8 & 2.74 & 79.3 & 1.87 & 80.5 & 2.08 & 90.5 & 2.32 \\
\hline$(R)-\mathrm{PHO}$ & $80 \mathrm{ng} \mathrm{L}^{-1}$ & 74.0 & 7.45 & 92.8 & 3.29 & 90.5 & 19.9 & 95.8 & 9.56 \\
\hline & $220 \mathrm{ng} \mathrm{L}^{-1}$ & 81.1 & 4.79 & 89.7 & 11.1 & 79.8 & 2.08 & 101 & 5.79 \\
\hline & $380 \mathrm{ng} \mathrm{L}^{-1}$ & 88.6 & 2.12 & 94.3 & 2.90 & 80.0 & 1.86 & 112 & 2.76 \\
\hline
\end{tabular}

a RSD is the relative standard deviation.

b $\mathrm{E} 1$ is the first-eluted enantiomer.

c $\mathrm{E} 2$ is the second-eluted enantiomer.

to assess the accuracy and intra- and inter-batch precision. The accuracy ranged from $79.3 \%$ to $118 \%$, as described in Table 4 , in agreement with international criteria, which recommends accuracy between 80 and $120 \%$. Precision was expressed by the RSD of the replicate measurements and the results (Table 4) show that this method is precise, with the mean concentration within $15 \%$ of the nominal values for the QC samples (14.2\%), except for the lowest QC which is within $20 \%$ of the nominal value (19.9\%), according to the international criteria [47].
All figures of merit are presented in Table 5. The calibration curves were performed using the external calibration method since labelled standards for all compounds are not available [43]. The approach of isotopic internal standard calibration is only appropriate when the internal standard chemical structure is the same or very similar to the target compound $[13,33]$. This issue has been discussed regarding parent drugs and its metabolites and bias from using a single isotopical internal standard for a class of compounds have been reported [51]. The injection of the 
Table 5

Linearity, range, instrument detection and quantification limits and method detection and quantification limits.

\begin{tabular}{|c|c|c|c|c|c|c|c|c|}
\hline Analyte & Range (ng L ${ }^{-1}$ ) & Calibration curve equation & $r^{2}$ & $\mathrm{RSD}^{\mathrm{a}}$ & $\operatorname{IDL}^{\mathrm{b}}\left(\mathrm{ng} \mathrm{L}^{-1}\right)$ & $\operatorname{IQL}^{\mathrm{c}}\left(\mathrm{ng} \mathrm{L}^{-1}\right)$ & $\operatorname{MDL}^{\mathrm{d}}\left(\mathrm{ng} \mathrm{L}^{-1}\right)$ & $\mathrm{MQL}^{\mathrm{e}}\left(\mathrm{ng} \mathrm{L}^{-1}\right)$ \\
\hline$(S)$-FLX & $20-400$ & $y=11078.9 x+117283.5$ & 0.9965 & 3.51 & 936 & 2835 & 3.74 & 11.3 \\
\hline$(R)-\mathrm{FLX}$ & $20-400$ & $y=9377.7 x+170109$ & 0.9934 & 4.01 & 2102 & 4870 & 8.41 & 19.5 \\
\hline$(S)-N F L X$ & $30-400$ & $y=1226.6 x+624.0$ & 0.9998 & 8.22 & 1317 & 3990 & 5.27 & 16.0 \\
\hline$(R)-\mathrm{NFLX}$ & $30-400$ & $y=1274.0 x+374.46$ & 0.9986 & 4.87 & 243 & 737 & 0.97 & 2.95 \\
\hline$(S)$-VNF & $20-400$ & $y=8019.3 x-8451.3$ & 0.9983 & 4.53 & 428 & 1296 & 1.71 & 5.18 \\
\hline$(R)-\mathrm{VNF}$ & $20-400$ & $y=8055.1 x-11168$ & 0.9978 & 5.45 & 2454 & 4935 & 9.82 & 19.7 \\
\hline$(R)-\mathrm{SBT}$ & $20-400$ & $y=2099.4 x+5219.1$ & 0.9963 & 8.03 & 1267 & 3838 & 5.07 & 15.4 \\
\hline$(S)-\mathrm{SBT}$ & $20-400$ & $y=2126.6 x+5527.5$ & 0.9940 & 7.06 & 1574 & 4769 & 6.29 & 19.1 \\
\hline$(S)$-ALP & $20-400$ & $y=2859.9 x-2476$ & 0.9991 & 5.26 & 1129 & 3421 & 4.52 & 13.7 \\
\hline$(R)$-ALP & $20-400$ & $y=2903.1 x-1926.6$ & 0.9990 & 5.68 & 2019 & 1618 & 8.08 & 18.5 \\
\hline BSP E $^{f}$ & $20-400$ & $y=11992 x-18347$ & 0.9973 & 3.90 & 696 & 2109 & 2.78 & 8.44 \\
\hline BSP E2 $^{g}$ & $20-400$ & $y=12261 x-17495$ & 0.9982 & 4.59 & 1134 & 3436 & 4.54 & 13.8 \\
\hline (S)-MET & $20-400$ & $y=1247.8 x-1414.4$ & 0.9992 & 6.80 & 843 & 2555 & 3.37 & 10.2 \\
\hline (R)-MET & $20-400$ & $y=1283.3 x-1934$ & 0.9981 & 6.29 & 2868 & 3690 & 11.5 & 14.8 \\
\hline (S)-PHO & $20-400$ & $y=2564.9 x-3130.5$ & 0.9982 & 5.05 & 163 & 495 & 0.65 & 1.98 \\
\hline (R)-PHO & $20-400$ & $y=2489.2 x-1573.4$ & 0.9987 & 5.48 & 492 & 1490 & 1.97 & 5.96 \\
\hline
\end{tabular}

a RSD is the relative standard deviation.

b IDL is the instrument detection limit.

c IQL is the instrument quantification limit.

d MDL is the method detection limit.

e MQL is the method quantification limit.

${ }^{f} \mathrm{E} 1$ is the first-eluted enantiomer.

$\mathrm{g}$ E2 is the second-eluted enantiomer.

reconstituted ethanolic extracts gave coefficients of determination between 0.9934 and 0.9998 in the range of $20-400 \mathrm{ng} \mathrm{L}^{-1}$ for all enantiomers, except for NFLX which range covered $30-400 \mathrm{ng} \mathrm{L}^{-1}$ [52]. Fig. 1 shows mass chromatograms and mass spectra of laboratory AGS-SBR samples spiked with $60 \mathrm{ng} \mathrm{L}^{-1}$ of all enantiomers and extracted by SPE on MCX cartridges. The range of method detection and quantification limits were $0.65-11.5 \mathrm{ng} \mathrm{L}^{-1}$ and $1.98-19.7 \mathrm{ng} \mathrm{L}^{-1}$, respectively [47].

\subsection{Matrix effects}

The post-extraction addition method carried out on laboratoryscale AGS-SBR samples indicated matrix effects between 71.0 and $112 \%$, with most of the compounds having signal suppression except FLX. Matrix effect is attributed to the effect of matrix composition on the electrospray ion source, which will affect the ionization capacity of the compounds and their signal response [43]. Although the values differ between different compounds due to their different chemical nature, the sample preparation procedure in this method is adequate and values achieved for matrix effects are acceptable and considered better than similar published works, allowing low quantification limits in the order of $\mathrm{ng} \mathrm{L}^{-1}$ $[16,34,43]$. Table 6 gives the matrix effects of all enantiomers as the percentage ratio between the post-spiked extracts and ethanolic solutions. As can be observed in Table 6, the matrix effect is similar for each pair of enantiomers. Even the probable chiral nature of the matrix which contains bacterial cells did not lead to differences in matrix effect for each pair of enantiomers.

\subsection{Quantification of WWTP effluents}

The developed and validated method was used to quantify the EF of the target pharmaceuticals in WWTP samples collected from the final effluent of the secondary clarifier of three WWTP located in the North of Portugal. The positive confirmation of all enantiomers was based on the SRM transition ratio between the precursor ion $\mathrm{m} / \mathrm{z}$ and the second most abundant fragment, according with European criteria [53]. Additionally, the deviations of the retention times for each enantiomer in the samples were below $2.5 \%$ when compared with the standards spiked in the matrix [53]. Regarding the antidepressants, only the $(R)$-FLX was detected in the WWTP 1 and 3 , indicating a faster degradation of $(S)$-FLX during the biological degradation occurring at those WWTP (Table 7). These findings are in accordance with MacLeod et al. (2007) who verified an enrichment in (R)-FLX [28]. Nevertheless, Barclay et al. (2012) found $(S)$-FLX concentration higher than $(R)$-FLX at the inlet and outlet of a WWTP [13]. Enantiomers of VNF were found between 40.4 and $129 \mathrm{ng} \mathrm{L}^{-1}$ in the three studied WWTP, with a similar EF, which values were between 0.54 and 0.55 (Table 7 and Fig. 2), similar to previous works that found VNF different from racemic $[11,30,34]$. Both anti-depressants exhibited an EF different from 0.5 proving that they were not racemic at the end of the WWTP treatment. Regarding beta-blockers, both enantiomers of BSP and PHO were found in the three WWTP and MET was found in two of the WWTP studied, all under their MQL (Table 7 and Fig. 2). PHO and MET enantiomers were already found in WWTP effluents at quantifiable concentrations [10,22-24,28,29,49]. Both the metabolite NFLX and the beta ${ }_{2}$-agonist SBT were not found in any of the analysed WWTP. Barclay et al. (2012) found enantiomers of NFLX at quantifiable concentrations [13]. SBT enantiomers were found at ng $\mathrm{L}^{-1}$

Table 6

Matrix effects of laboratory-scale AGS-SBR for all enantiomers.

\begin{tabular}{ll}
\hline Enantiomer & Matrix effect $(\%)$ \\
\hline$(S)$-FLX & 110 \\
$(R)$-FLX & 112 \\
$(S)$-NFLX & 86.6 \\
$(R)-\mathrm{NFLX}$ & 86.1 \\
$(S)$-VNF & 87.3 \\
$(R)$-VNF & 87.9 \\
$(R)$-SBT & 71.0 \\
$(S)$-SBT & 73.7 \\
$(S)$-ALP & 82.8 \\
$(R)$-ALP & 84.1 \\
BSP E1 & 81.3 \\
BSP E2 & 83.4 \\
$(S)-$ MET & 81.1 \\
$(R)$-MET & 81.7 \\
$(S)$-PHO & 74.8 \\
$(R)-P H O$ & 73.9 \\
\hline
\end{tabular}

Matrix effect $(\%)=A / B \times 100$, where $A$ is the area obtained for the laboratory-scale AGS-SBR samples spiked with all enantiomers $\left(220 \mathrm{ng} \mathrm{L}^{-1}\right)$ and extracted by SPE and $B$ is the area obtained for an ethanolic solution with all enantiomers at the same concentration as the reconstituted spiked extracted samples.

a $\mathrm{E} 1$ is the first-eluted enantiomer.

b $\mathrm{E} 2$ is the second-eluted enantiomer. 
Table 7

Average concentrations ( $\mathrm{ng} \mathrm{L}^{-1}$ ) and EF with the respective standard deviations of the target pharmaceuticals at the three WWTP.

\begin{tabular}{|c|c|c|c|c|c|c|}
\hline \multirow[t]{2}{*}{ Analyte } & \multicolumn{2}{|l|}{ WWTP1 ${ }^{\mathrm{a}}$} & \multicolumn{2}{|l|}{ WWTP2 $^{\mathrm{a}}$} & \multicolumn{2}{|l|}{ WWTP3a } \\
\hline & Concentration (ng L $\left.{ }^{-1}\right)$ & $\mathrm{EF}^{\mathrm{b}}\left(\mathrm{SD}^{\mathrm{c}}\right)$ & Concentration (ng L $\left.{ }^{-1}\right)$ & $\mathrm{EF}^{\mathrm{b}}\left(\mathrm{SD}^{\mathrm{c}}\right)$ & Concentration $\left(\mathrm{ng} \mathrm{L}^{-1}\right)$ & $\mathrm{EF}^{\mathrm{b}}\left(\mathrm{SD}^{\mathrm{c}}\right)$ \\
\hline$(S)$-FLX & $<\mathrm{MDL}^{\mathrm{d}}$ & - & $<\mathrm{MQL}$ & - & $<\mathrm{MDL}$ & - \\
\hline (R)-FLX & $<\mathrm{MQL}^{\mathrm{e}}$ & & $<\mathrm{MQL}$ & & $<\mathrm{MQL}$ & \\
\hline$(S)$-VNF & $129( \pm 11.5)$ & $0.54( \pm 0.02)$ & $125( \pm 13.0)$ & $0.55( \pm 0.01)$ & $48.6( \pm 3.02)$ & $0.55( \pm 0.01)$ \\
\hline$(R)-\mathrm{VNF}$ & $110( \pm 6.94)$ & & $102( \pm 7.94)$ & & $40.4( \pm 1.79)$ & \\
\hline BSP E1 $^{\mathrm{f}}$ & $<\mathrm{MQL}$ & - & $<\mathrm{MQL}$ & - & $<\mathrm{MQL}$ & - \\
\hline BSP E2 ${ }^{g}$ & $<\mathrm{MQL}$ & & $<\mathrm{MQL}$ & & $<\mathrm{MQL}$ & \\
\hline$(S)-\mathrm{MET}$ & $<\mathrm{MQL}$ & - & $<\mathrm{MQL}$ & - & $<\mathrm{MDL}$ & - \\
\hline$(R)-\mathrm{MET}$ & $<\mathrm{MQL}$ & & $<\mathrm{MQL}$ & & $<\mathrm{MDL}$ & \\
\hline (S)-PHO & $<\mathrm{MQL}$ & - & $<\mathrm{MQL}$ & - & $<\mathrm{MQL}$ & - \\
\hline (R)-PHO & $<\mathrm{MQL}$ & & $<\mathrm{MQL}$ & & $<\mathrm{MQL}$ & \\
\hline
\end{tabular}

a WWTP is the wastewater treatment plant.

b $\mathrm{EF}$ is the enantiomeric fraction.

c $\mathrm{SD}$ is the standard deviation.

d MDL is the method detection limit.

e MQL is the method quantification limit.

$\mathrm{f} \mathrm{E} 1$ is the first-eluted enantiomer.

$g$ E2 is the second-eluted enantiomer.
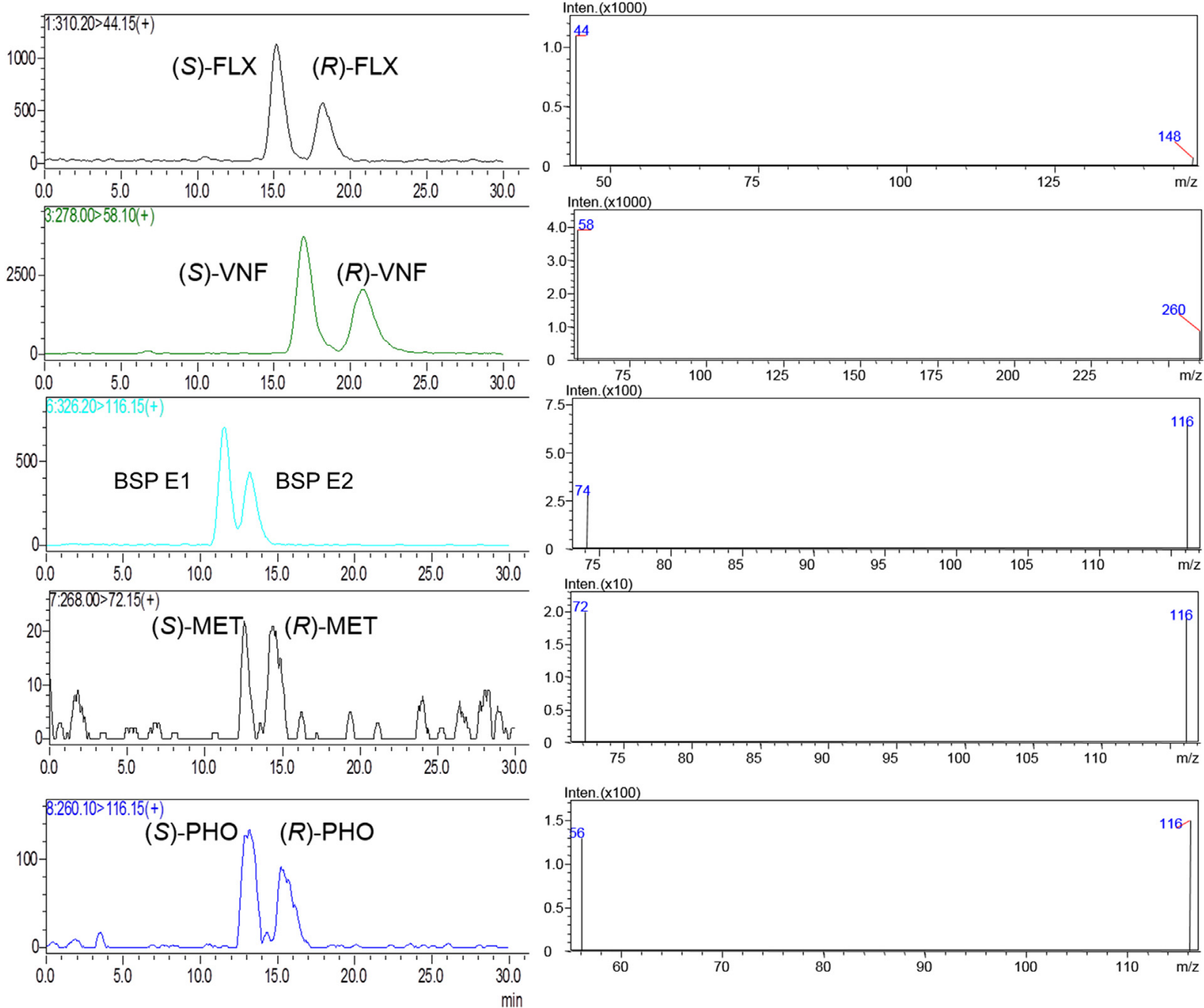

Fig. 2. Mass chromatograms and mass spectra of WWTP2 effluent sample, showing the enantiomers of FLX, VNF, BSP, MET and PHO.

concentration in the effluents of WWTP [28,29,49]. As it was expected ALP was also not found in the WWTP, since this pharmaceutical is not sold in Portugal. Inclusion of ALP in the study widens the application of the method to locations where it is commercialized.

\section{Conclusions}

A SPE-LC-MS/MS method with a triple quadrupole mass analyser was optimized and validated for the quantification of enantiomers of three different therapeutic classes of $\mathrm{CP}$, namely 
selective serotonin reuptake inhibitors and a metabolite, betablockers and one beta ${ }_{2}$-adrenergic agonist. The LC-MS/MS method was developed with a Chirobiotic ${ }^{\mathrm{TM}} \mathrm{V}$ and an eco-friendly mobile phase constituted by ethanol and ammonium acetate buffer at low flow rate. The method quantification limits were below $19.7 \mathrm{ng} \mathrm{L}^{-1}$ for all enantiomers and allowed the successful quantification of enantiomers from WWTP effluents. The confirmation of the enantiomers found, $(R)$-FLX or both enantiomers of FLX and both enantiomers of VNF, BSP, MET and PHO, was based in two SRM transitions, its ion ratios and retention times, according to European Commission Decision 2002/657/EC. This method proved to be capable for monitoring enantiomers in WWTP effluents, and will be further used to assess degradation of CP in biodegradation studies. It can also be straightforwardly adapted to monitoring surface and estuarine waters. This study contributes for the urgent need of development of enantioselective methods for CP quantification in environmental matrices.

\section{Acknowledgments}

The work has been supported by Fundacão para a Ciência e Tecnologia-FCT ( $\mathrm{PhD}$ grant attributed to Ana Rita Ribeiro and Alexandra S. Maia, respectively, SFRH/BD/64999/2009 and SFRH/BD/86939/2012), from QREN-POPH, European Social Fund and MCTES. Authors also wish to acknowledge the support from national funds from FCT through projects FLUOROPHARMA, PTDC/EBB-EBI/111699/2009, PEstOE/EQB/LA0016/2013, CEQUIMED-PEst-OE/SAU/UI4040/2011 and PEst-C/EQB/LA0006/2013. This research was partially supported by the European Regional Development Fund (ERDF) through the COMPETE - Operational Competitiveness Programme and national funds through FCT, under the project PEst-C/MAR/LA0015/2011. The authors thank Paula Paíga for her collaboration.

\section{References}

[1] T.V. Madureira, J.C. Barreiro, M.J. Rocha, E. Rocha, Q.B. Cass, M.E. Tiritan, Sci. Total Environ. 408 (2010) 5513.

[2] T.V. Madureira, M.J. Rocha, Q.B. Cass, M.E. Tiritan, J. Chromatogr. Sci. 48 (2010) 176.

[3] L.H.M.L.M. Santos, P. Paíga, A.N. Araújo, A. Pena, C. Delerue-Matos, M.C.B.S.M. Montenegro, J. Chromatogr. B 930 (2013) 75

[4] L.H.M.L.M. Santos, M. Gros, S. Rodriguez-Mozaz, C. Delerue-Matos, A. Pena, D. Barceló, M.C.B.S.M. Montenegro, Sci. Total Environ. 461-462 (2013) 302.

[5] K. Kümmerer, Chemosphere 75 (2009) 417.

[6] K. Kümmerer, J. Environ. Manage. 90 (2009) 2354.

[7] A.R. Ribeiro, P.M.L. Castro, M.E. Tiritan, Environ. Chem. Lett. 10 (2012) 239.

[8] J.K. Stanley, A.J. Ramirez, C.K. Chambliss, B.W. Brooks, Chemosphere 69 (2007)

[9] F. De Andrés, G. Castañeda, Á. Ríos, Chirality 21 (2009) 751.

[10] V.K.H. Barclay, N.L. Tyrefors, I.M. Johansson, C.E. Pettersson, J. Chromatogr. A 1269 (2012) 208

[11] Z. Li, E. Gomez, H. Fenet, S. Chiron, Chemosphere 90 (2013) 1933.

[12] R. López-Serna, A. Jurado, E. Vázquez-Suñé, J. Carrera, M. Petrović, D. Barceló, Environ. Pollut. 174 (2013) 305
[13] V.K.H. Barclay, N.L. Tyrefors, I.M. Johansson, C.E. Pettersson, J. Chromatogr. A 1227 (2012) 105

[14] D.R. Baker, B. Kasprzyk-Hordern, Sci. Total Environ. 454-455 (2013) 442.

[15] J.C. Barreiro, K.L. Vanzolini, T.V. Madureira, M.E. Tiritan, Q.B. Cass, Talanta 82 (2010) 384

[16] J.C. Barreiro, K.L. Vanzolini, Q.B. Cass, J. Chromatogr. A 1218 (2011) 2865

[17] Q. Huang, K. Zhang, Z. Wang, C. Wang, X. Peng, Anal. Bioanal. Chem. 403 (2012) 1751

[18] H.-R. Buser, T. Poiger, M.D. Muller, Environ. Sci. Technol. 33 (1999) 2529.

[19] V. Matamoros, M. Hijosa, J.M. Bayona, Chemosphere 75 (2009) 200.

[20] N.H. Hashim, S.J. Khan, J. Chromatogr. A 1218 (2011) 4746.

[21] N.H. Hashim, R.M. Stuetz, S.J. Khan, Chirality 25 (2013) 301

[22] L.J. Fono, D.L. Sedlak, Environ. Sci. Technol. 39 (2005) 9244.

[23] L.J. Fono, E.P. Kolodziej, D.L. Sedlak, Environ. Sci. Technol. 40 (2006) 7257.

[24] U. Kunkel, M. Radke, Water Res. 46 (2012) 5551.

[25] S. Morante-Zarcero, I. Sierra, J. Pharm. Biomed. Anal. 62 (2012) 33

[26] S. Morante-Zarcero, I. Sierra, Chirality 24 (2012) 860.

[27] L.N. Nikolai, E.L. McClure, S.L. MacLeod, C.S. Wong, J. Chromatogr. A 1131 (2006) 103.

[28] S.L. MacLeod, P. Sudhir, C.S. Wong, J. Chromatogr. A 1170 (2007) 23.

[29] S.L. MacLeod, C.S. Wong, Water Res. 44 (2010) 533.

[30] B. Kasprzyk-Hordern, D.R. Baker, Environ. Sci. Technol. 46 (2012) 1681.

[31] J.P. Bagnall, S.E. Evans, M.T. Wort, A.T. Lubben, B. Kasprzyk-Hordern, J. Chromatogr. A 1249 (2012) 115

[32] G. Gasser, I. Pankratov, S. Elhanany, P. Werner, J. Gun, F. Gelman, O. Lev, Chemosphere 88 (2012) 98.

[33] V.K.H. Barclay, N.L. Tyrefors, I.M. Johansson, C.E. Pettersson, J. Chromatogr. A 1218 (2011) 5587.

[34] B. Kasprzyk-Hordern, V.V.R. Kondakal, D.R. Baker, J. Chromatogr. A 1217 (2010) 4575.

[35] A.R. Ribeiro, A.S. Maia, Q.B. Cass, M.E. Tiritan, J. Chromatogr. B doi:10.1016/j.jchromb.2014.02.049.

[36] A.R. Ribeiro, A.S. Maia, I.S. Moreira, C.M. Afonso, P.M.L. Castro, M.E. Tiritan, Chemosphere 95 (2014) 589.

[37] A. Detroyer, Y. Vander Heyden, S. Carda-Broch, M.C. Garcí́a-Alvarez-Coque, D.L. Massart, J. Chromatogr. A 912 (2001) 211.

[38] http://pubchem.ncbi.nlm.nih.gov/summary/summary.cgi?cid=5656, accessed on May 2014.

[39] http://www.drugbank.ca/drugs/DB01001, accessed on May 2014.

[40] C.L. Amorim, A.S. Maia, R.B.R. Mesquita, A.O.S.S. Rangel, M.C.M. van Loosdrecht, M.E. Tiritan, P.M.L. Castro, Water Res. 50 (2014) 101

[41] A.F. Duque, V.S. Bessa, M.F. Carvalho, M.K. de Kreuk, M.C.M. van Loosdrecht, P.M.L. Castro, Water Res. 45 (2011) 6745

[42] I.S. Moreira, C.L. Amorim, A.R. Ribeiro, R.B.R. Mesquita, A.O.S.S. Rangel, M.E. Tiritan, P.M.L. Castro, Chemosphere 111 (2014) 103

[43] T.V. Madureira, J.C. Barreiro, M.J. Rocha, Q.B. Cass, M.E. Tiritan, J. Chromatogr. A 1216 (2009) 7033.

[44] A.S. Maia, A.R. Ribeiro, C.L. Amorim, J.C. Barreiro, Q.B. Cass, P.M.L. Castro, M.E. Tiritan, J. Chromatogr. A 1333 (2014) 87.

[45] A.R. Ribeiro, C.M. Afonso, P.M.L. Castro, M.E. Tiritan, Ecotoxicol. Environ. Saf. 87 (2013) 108

[46] A.R. Ribeiro, C.M. Afonso, P.M.L. Castro, M.E. Tiritan, Environ. Chem. Lett. 11 (2013) 83.

[47] FDA, U.S. Food and Drug Administration, 2001, p. 1.

[48] M. Farré, S. Pérez, C. Gonçalves, M.F. Alpendurada, D. Barceló, Trends Anal. Chem. 29 (2010) 1347.

[49] R. López-Serna, B. Kasprzyk-Hordern, M. Petrović, D. Barceló, Anal. Bioanal. Chem. 405 (2013) 5859.

[50] K. Bielicka-Daszkiewicz, A. Voelkel, Talanta 80 (2009) 614

[51] W. Jian, R.W. Edom, Y. Xu, J. Gallagher, N. Weng, J. Chromatogr. B 878 (2010) 3267.

[52] Guideline on Bioanalytical Method Validation, EMEA/CHMP/EWP/192217/ 2009, European Medicines Agency, London, United Kingdom, 2011, p. 1.

[53] Commission Decision of 12 August 2002 Implementing Council Directive 96/23/EC Concerning the Performance of Analytical Methods and the Interpretation of Results, Official Journal of the European Communities, 2002, p. 8. 